\title{
ESPECULAÇÕES SOBRE A AUTOPOIESE DA NARRATIVA LITERÁRIA
}

\author{
Guilherme Preger ${ }^{1}$ \\ Universidade Estadual do Rio de Janeiro (UERJ) \\ gfpreger@yahoo.com.br
}

\begin{abstract}
Resumo
O trabalho propõe uma reflexão especulativa sobre a narrativa literária como subsistema autopoiético social, como extensão do conceito teórico de Niklas Luhmann de autopoiese (autopoiesis), aplicado nas ciências sociais. Nossa hipótese especula como a narrativa literária pode ser descrita como uma forma de comunicação social e de "observação de segunda ordem" (observação da observação). No entanto, a narrativa literária se distingue da narrativa social como uma "auto-observação" narrativa ou narrativa da narrativa. O que interessa à narrativa literária não é a descrição de fatos, ações ou personagens, mas as relações de níveis narrativos no momento de sua autorreprodução. Com isso, será proposto um cruzamento entre a Teoria dos Sistemas Sociais de Luhmann com a Teoria da Narratologia, em particular como apresentada na obra de Gerard Genette. Assim, a diferença entre o nível narrativo (diegesis) e o nível de focalização da história corresponde à diferença entre observação de segunda e de primeira ordens. Será visto que a resolução dos paradoxos surgidos na circularidade da auto-observação do sistema literário é realizada pela formação de "cronotopos", conceito da obra de Mikhail Bakhtin, isto é, como uma extensão no tempo e no espaço do domínio do imaginário.
\end{abstract}

Palavras-chave: Autopoiese. Narrativa. Niklas Luhmann.

\section{SOME SPECULATIONS ABOUT THE AUTOPOIESIS OF LITERARY NARRATIVE}

\begin{abstract}
The paper proposes a speculative reflection on the literary narrative as autopoietic social subsystem, as an extension of the theoretical concept of Niklas Luhmann of autopoiesis, applied in the social sciences. Our hypothesis speculates how the literary narrative can be described as a form of social communication and "observation of second order" (observation of observation). However, the literary narrative is distinguished from the social narrative as a "self-observation" narrative or narrative of the narrative. What does literary narrative is not the description of facts, actions or characters, but the presentation of narrative levels at the time of his selfreproduction. With this, will be proposed a link between the theory of social systems as presented in Luhmann's work and Narratology, especially as presented in the work of Gerard Genette. Thus, the difference between the narrative level (diegesis) and the external focalization level corresponds to the difference between observation of second and first orders. It will be seen that the resolution of the paradoxes that have arisen by the circularity of self-observation literary system is accomplished by the formation of "cronotopos" concept of the work of Mikhail Bakhtin, i.e. as an extension in time and space of the imaginary domain.
\end{abstract}

Keywords: Autopoiesis. Narrative. Niklas Luhmann.

1 Doutorando em Teoria da Literatura e Literatura Comparada do Programa de Pós-Graduação de Letras da UERJ. 


\section{INTRODUÇÃO}

Este trabalho faz parte de minha pesquisa em andamento de Doutorado, Fábulas da Ciência. Neste, procuro investigar o uso da narrativa no universo discursivo das ciências ou como as ciências narram ou relatam suas atividades. As narrativas científicas não são especificamente literárias, porém em trabalho posterior pretendo fazer aproximações entre tais formas de narrar e as narrativas literárias, especialmente do gênero que se convencionou chamar de ficção científica.

Este presente trabalho seguirá um trajeto mais teórico para discutir a questão da narrativa como prática social. Duas teses são propostas: 1- narrativas são práticas discursivas socialmente generalizadas; 2- narrativas literárias compõem um conjunto restrito do universo abrangente da narrativa social, com especificidades próprias. Em suma, este trabalho se propõe a procurar uma compreensão da especificidade própria da narrativa literária enquanto elemento de um sistema social.

Essas duas teses, na verdade, abordam um problema bastante complexo, ou mesmo controverso, sobre a função literária nas práticas discursivas da sociedade. Aqui se tentará inicialmente traçar um esboço de abordagem para orientar uma pesquisa futura. Esta abordagem procura articular dois repertórios teóricos que raramente são analisados em conjunto: a teoria dos sistemas autopoiéticos de Niklas Luhmann e a narratologia, tal como descrita nos trabalhos de Gerard Genette. Essa articulação foi discutida pioneiramente na obra de Bruce Clarke (2014), uma das referências deste trabalho.

Sumariamente, a teoria de Niklas Luhmann descreve a sociedade como um sistema exclusivamente composto de "comunicações". De maneira controversa, Luhmann exclui de sua definição de sociedade os "sistemas psíquicos". O sociólogo haure sua teoria social da teoria dos sistemas e retira dela dois conceitos fundamentais: sistema e comunicação. Sistema se define por qualquer operação de distinção entre sistema e entorno (Umwelt) ou ambiente. Ou seja, o próprio sistema gera a distinção entre si e o entorno. Essa distinção é produzida através de um ato de observação. Luhmann descreve dois tipos de observação: a observação de primeira ordem e a observação de segunda ordem. Na observação de primeira ordem, um sistema observa outro sistema. Na de segunda ordem, um sistema observa a si próprio observando, ou seja, é uma "observação da observação". A observação de segunda ordem é essencial para o sistema gerar a distinção entre ele e seu entorno e para se autorreproduzir, isto é, criando seus próprios elementos. A autopoiese (autopoiesis) significa a autorreprodução de um sistema. Para alcançar essa possibilidade é necessário estabelecer um "fechamento operacional", isto é, criar uma 
circularidade lógica que define internamente suas próprias condições de reprodução. O sistema autopoiético não necessita do ambiente para poder se reproduzir, mas se utiliza de sua própria estrutura interna. O ambiente lhe serve apenas de um "meio" (medium) para realizar suas operações de autorreprodução.

Para Luhmann, a sociedade é um tipo de sistema autopoiético, diferente dos sistemas psíquicos e dos sistemas bióticos (organismos), que é composto de eventos chamados de comunicação. Uma comunicação é um evento composto da unidade de três seleções: mensagem, informação e compreensão ${ }^{2}$. Compreensão não significa entendimento semântico de um conteúdo, mas sim entendimento de determinada "irritação" de um sistema em outro como comunicação. Essa compreensão se dá através de outra comunicação. Assim, de comunicação em comunicação, o sistema se reproduz autopoieticamente, evoluindo de maneira imprevisível.

\section{SISTEMAS AUTOPOIÉTICOS E NARRATOLOGIA}

Toda comunicação é um evento bastante improvável porque depende de uma "dupla contingência": a de que tanto o emissor, denominado de "ego", quanto o receptor, denominado de "alter", sejam capazes de compreender a comunicação num universo muito mais amplo de "ruído". O mais provável é que a comunicação não consiga se autorreproduzir. Para garantir ou aumentar a probabilidade de comunicação, a sociedade, enquanto sistema, a partir da modernidade, se distinguiu em subsistemas de "diferenciação funcional" que, através de "programas", permitem operar mais facilmente (com maior probabilidade) suas distinções internas, isto é, suas comunicações. Assim, surgiram os subsistemas da política, da economia, do direito, da ciência ou da arte, entre outros. Cada um desses subsistemas possui um programa de distinções binário que permite aceitar ou rejeitar uma comunicação. O subsistema de direito, por exemplo, define um programa de distinção binária legítimo-ilegítimo. O subsistema de ciência, a distinção verificável-não verificável. O subsistema de arte, a distinção belo-feio.

A questão que se coloca, portanto, é sobre a possibilidade do campo literário, a exemplo de outros campos, ter se tornado um subsistema diferenciado. Seu programa seria então a distinção entre o que é literário e o que não é literário. Não deixa de surpreender, portanto, desde o século XIX, a formação de diversos “cânones” literários, que cumpririam basicamente a função do programa de distinção. É importante observar que toda distinção é absolutamente

${ }^{2}$ Mitteilung, Information e Verstehen no original (STAMFORD DA SILVA, 2016). 
contingente e varia de "operação" à “operação" e de "comunicação à comunicação". Cada obra literária, nesse aspecto, seria uma comunicação composta de três seleções: mensagem (texto, discurso, enunciação), informação (enunciado, história, forma) e compreensão. A compreensão seria o de entender uma determinada produção textual como literária. Essa compreensão varia com o tempo, sob uma forma "evolutiva", segundo Luhmann. A recente controvérsia sobre a premiação Nobel (2016) ao compositor Bob Dylan demonstra que a cada momento histórico a compreensão do que é literário se altera. Porém, uma obra considerada como literária participa de um subsistema social através de um circuito de conversação, como definiu Vilém Flusser a respeito de Kafka: Uma obra literária é a articulação de um intelecto. É a forma linguística na qual um
intelecto se realiza. Realizando-se, o intelecto participa da conversação geral. Uma
obra literária é, portanto, um elo da cadeia da grande conversação que podemos,
grosso modo, chamar de "civilização". Como parte integrante da conversação tem a
obra literária dois aspectos básicos: encerra a conversação que a precede e origina a
conversação que a sucede.
No primeiro aspecto é uma resposta. No segundo, uma provocação. Há, portanto, duas
possibilidades fundamentais de apreciação de uma dada obra literária: podemos tentar
compreendê-la como resposta, ou podemos tentar enfrentá-la como provocação. Na
primeira tentativa estaremos analisando a obra. Na segunda estaremos conversando
com ela. (FLUSSER, 2002).

Mas como caracterizar especificamente a distinção do que é literário em sua contingência radical? Lembrando que todo sistema se distingue de seu entorno graças a uma observação e gerando, nesse movimento, um limite ou uma fronteira que define para cada evento se ele pertence ou não ao sistema. Se o evento pertence, ele é incorporado a si como “informação". Caso não pertença, ele é "descartado" como ruído. Cada evento, ou cada comunicação, está, portanto, sempre na "fronteira" e é uma "unidade complexa", distinguindo aquilo que é sistema e aquilo que não é sistema (ambiente). No caso da literatura, a distinção se dá entre o que é literário e o que é extraliterário.

O teórico Michael Korfmann, em seu artigo A literatura moderna como observação de segunda ordem. Uma introdução ao pensamento sistêmico de Niklas Luhmann (2002), procurou definir uma extensão do conceito da teoria dos sistemas sociais para abarcar a literatura, uma vez que o próprio Niklas Luhmann não abordou a questão literária, embora tenha trabalhado sobre a questão estética das artes plásticas (LUHMANN, 1996). Neste texto, o sociólogo alemão propôs o conceito de "estilo" para substituir o programa de decisão da arte, entre os valores de "belo" e "feio". No entanto, o autor confessa ao final que a eficácia de sua proposta é inconclusiva (idem).

A proposta de Korfmann, por outro lado, é a de considerar a literatura como observação de segunda ordem. No entanto, essa definição é por demais genérica, pois assim a literatura 
estaria presente em outros subsistemas funcionais, todos dependentes de observações de segunda ordem. Em seguida, no entanto, ele restringe a sua definição mais precisamente:

\begin{abstract}
Sua narratividade como arte textual mostra que e como se pode ganhar forma e reflete, na oscilação entre a observação de primeira e segunda ordem, a posição do observador entre a cegueira, a diferenciação utilizada e a visibilidade, o descrito. Neste contexto, a literatura não representa um mundo dado, mas observa o observar e as observações do mundo, quer dizer, a comunicação literária confronta o leitor com uma observação de segunda ordem referente a operações de diferenciar, descrever e estabelecer sentido. Além do mais, leva em consideração que diferenciações são usadas para observar e descrever. Assim, a literatura observa e presta atenção a diferenças das quais depende o que pode ser visto e o que não.” (KORFMANN, 2002).
\end{abstract}

O conceito de literatura é substituído pelo de "narratividade", na proposta de Korfmann, e esta estaria presente na relação das observações de primeira e segunda ordem, ou entre cegueira e visibilidade nas palavras do teórico. Assim, se consideramos não a literatura em geral, mas a narrativa especificamente, esta seria a forma comunicativa e social da observação de segunda ordem e, portanto, presente em todos os discursos dos subsistemas diversos, estando de acordo com nossa primeira tese sobre seu caráter generalizado socialmente. Para entender melhor essa tese, devemos observar que Luhmann rejeita o conceito de ação como elemento social, sendo essa talvez sua contribuição mais original, em contraste com muitas outras teorias da sociedade para as quais a ação é a característica fundamental. Para o sociólogo alemão, é a comunicação o elemento social unitário e não a ação. O recurso a descrever a sociedade em termos de ação e atores ou agentes se deve a uma redução da observação social da segunda para primeira ordem. Quando observamos um sistema social a partir de um foco externo, tendemos a ver esse sistema como uma relação entre atores e suas ações (SEIDL, 2006, p.34). Porém, apenas a observação de segunda ordem permite observar a sociedade como comunicação. A narrativa seria então o modo social de promover essa observação de segunda ordem, distinguindo-se da observação de primeira ordem, que podemos simplesmente denominar de "descrição".

Esta ideia lembra a distinção empregada pelo crítico György Lukács em seu célebre ensaio Narrar ou descrever, em que ele criticava os romances naturalistas pelo excesso de descrição em oposição ao narrar do romance realista clássico (LUKÁCS, 1965). Segundo o crítico, os romances naturalistas seguiam o paradigma científico positivista (do século XIX) ${ }^{3}$ de privilegiar a descrição como modo de discurso. Trata-se de uma tese problemática, pois todo ato da narrativa, como vimos, é uma observação de segunda ordem e todos os romances, sejam realistas ou naturalistas, envolvem narrativa. No entanto, o teórico húngaro distingue dois

\footnotetext{
3 "O método da observação e descrição surge com o intento de tornar científica a literatura, transformando-a numa ciência natural aplicada, em uma sociologia" (LUKÁCS, 1965, p. 76).
} 
modos de discurso e os divide segundo sua predominância no romance novecentista. Ele rebaixa os romances naturalistas em detrimento dos romances realistas, como dois modos de composição referentes a organizações sociais diferentes. Entretanto, no lugar de pensar em termos de gênero, poder-se-ia distinguir modos de perspectiva no interior do próprio romance. Essa distinção se torna viável com o conceito de "focalização" que será desenvolvido pela narratologia, como veremos a seguir. Porém, é interessante Lukács propor em seu ensaio a oposição entre narrar e descrever como homóloga à distinção entre participar e observar ${ }^{4}$. Nos termos deste trabalho, participar seria, portanto, a forma existencial de uma observação de segunda ordem e o discurso de participação, um discursivo narrativo em estrito senso.

A perspectiva de Lukács encontra afinidades nos trabalhos posteriores da teoria da narratologia. Em tudo semelhante ao gesto de Luhmann, a grande inovação desta corrente teórica é considerar a narrativa não como um relato de ações de personagens ou "actantes", mas como "relato de eventos". Gerard Genette propõe como distinção principal a relação entre narrativa/relato (récit) e história, esta como o conjunto de eventos "contados" (racontés) e o relato como discurso oral ou verbal que os conta (há também a narração como o ato efetivo e situado de contar ou relatar a história). Fundamental é que, para Genette, a narratologia se refere aos modos de representação de uma história e não a seu tema (GENETTE, 1983, p; 11-12) .

A distinção genettiana evita a antiga distinção proposta pela retórica entre diegesis e mimesis, tal como formulada na República de Platão. Diegesis se refere ao relato contado por um poeta, como na épica, enquanto mimesis é a apresentação direta de personagens e ação como no drama teatral, quando não há mediação de um poeta. Para Genette, na arte romanesca só há, a rigor, diegesis e, eventualmente, uma "ilusão mimética" quando diálogos de personagens são apresentados diretamente. Neste caso, no entanto, o mais correto seria considerar como "relatos de palavras". Em outros termos, para Genette, na narrativa há sempre a mediação de um narrador e de seu relato, mesmo quando este está supostamente ausente ${ }^{5}$.

\footnotetext{
4“A alternativa participar ou observar corresponde, então, a duas posições socialmente necessárias, assumidas pelos escritores em dois sucessivos períodos do capitalismo. A alternativa narrar ou descrever corresponde aos dois métodos fundamentais de representação próprios destes dois períodos" (idem, p.53). Itálicos do autor.

5 "Eu me alinho sem menos e sem hesitação a esta coorte patética, de que o essencial do Discurso da narrativa, a começar por seu título, baseia-se no pressuposto desta instância enunciadora que é a narração, com o seu narrador e seu narratário, fictício ou não, representados ou não, quieta ou tagarela, mas ainda presente no que é bem para mim, receio, um ato de comunicação" ("Je me range néanmoins sans hésitation dans cette pitoyable cohorte, puisque l'essentiel de Discours du récit, à comencer pour son titre, repose sur l'assomption de cette instance énonciatrice qu' est la narration, avec son narrateur et son narrataire, fictifs ou non, representés ou non, silencieux ou bavards, mais toujours présents dans ce qui est bien pour moi, j'en peur, un acte de communication") (GENETTE, 1983, p. 68.).
} 
A distinção de Genette entre relato e história se dá assim como uma nova dobra no interior da diegese entre o que é dito e o que é visto, entre modos de dizer (voz) e modos de se ver (focalização). Os modos de dizer se dão na diferença de participação dos narradores, como narrador heterodiegético (fora da diegese) ou homodiegético (dentro da diegese). Os modos de ver estão diferenciados em perspectivas, ou focalizações. Focalização externa é a história vista/observada de "fora"; focalização interna é a história vista/observada de dentro (por um dos personagens), e focalização nula, ausente, ou variável a história vista por um narrador onisciente ou um narrador ausente (invisível). Assim, a focalização representa sempre, nas palavras de Genette (1983), uma "restrição de campo", ou restrição da "informação completa". Esta restrição é o que mais separa a diegese da mimese, pois nesta última, a informação da história é apresentada completa, enquanto na primeira a informação é filtrada pela perspectiva do narrador 6 .

Embora se possam traçar analogias entre a teoria dos sistemas, a narratologia e a obra de Lukács, em cada uma delas os conceitos têm especificidade própria e não são necessariamente equivalentes. No entanto, em todas essas obras teóricas se apontam tensões entre as formas de enunciação no interior do próprio discurso e os modos de observação. Se, em Lukács a distinção se faz entre narrar e descrever, na diferença entre modos de perspectivas que privilegiam ou o participar (narrar) ou o observar (descrever), em Genette toda narrativa é um jogo entre aquilo que é dito e aquilo que é visto e esse é sempre um jogo de tensões e contrastes. $\mathrm{O}$ contraste entre as formas de narrar do romance realista e do romance naturalista, segundo Lukács, é transposto por Genette como elementos de tensão no interior da própria narrativa. Em Luhmann, por sua vez, a distinção se dá entre observação de primeira ordem e de segunda ordem ${ }^{7}$. Podemos propor a seguinte homologia entre esta teoria e a narratologia: a

\footnotetext{
${ }^{6}$ Mesmo com a focalização nula, quando o narrador é onisciente e narra a história com absoluta informação, conhecendo mesmo os pensamentos dos personagens, ainda neste caso para Genette não se trata de mimese mas de diegese que produz uma "ilusão de mimese". Mieke Bal (1977) prefere denominar esse narrador de "narrador invisível". O narrador onisciente sempre deixa marca de sua narração no texto. Esta marca é o próprio discurso narrado como "objeto" da narração, para o qual o sujeito é o narrador em terceira pessoa (invisível).

${ }^{7}$ Em Luhmann, não há conceito de narrativa, apenas de descrição. Porém, toda descrição é sempre também autodescrição, pois um sistema ao observar observa a si mesmo. O ambiente não pode ser observado diretamente, mas apenas enquanto relação ao próprio sistema. No entanto, o sistema não pode se observar observando, pois o ato de observação é um ponto cego de sua própria operação. Assim, para descrever-se, o sistema precisa criar uma distância interna de si mesmo, como se observasse outro sistema (Luhmann denominará de "heterorreferencia" esta relação). A função da descrição é "fixar" a observação estruturalmente: "Descrições fixam uma estrutura ou um 'texto' para possíveis observações que podem agora ser feitas de forma mais sistemática, lembradas e transmitidas mais facilmente, e que agora podem ser conectadas melhor umas a outras" ("Descriptions fix a structure or a 'text' for possible observations which can now be made more systematically, remembered and handed down more easily, and which can now be connected better to each other") (LUHMANN E FUCHS, 1988). Portanto, Luhmann não transpõe a distinção entre observação de primeira ordem e de segunda ordem para seu
} 
focalização externa com narrador heterodiegético (o narrador que descreve uma trama da qual não participa) é uma observação de primeira ordem. Se a narração é homodiegética com focalização interna (narrador no interior da história, observando-a a partir de dentro), temos uma observação de segunda ordem. No entanto, mesmo o narrador heterodiegético com focalização externa precisa se relacionar com sua narrativa, isto é, com sua posição de narrador, ainda que esta se torne obscurecida pelo ato de descrição de um "mundo exterior", pois esta descrição marca uma distinção entre a situação do narrador e a situação dos "eventos" narrados. Nesta distinção entre situações narrativas e entre suas respectivas e mútuas determinações reside uma das características da arte literária que é a relação entre os níveis narrativos, de narrativas no interior da narrativa, como veremos a seguir.

Niklas Luhmann mostrou que toda observação de segunda ordem conduz sempre à circularidade, pois é uma observação de si própria, observação do próprio ato de observação (LUHMANN, 1995) ${ }^{8}$, pois essa circularidade não pode ter inteiro sucesso sem gerar contradições. Assim, a circularidade gera, no extremo, duas formas de autodescrição do sistema: a tautologia (o sistema é o que é) e o paradoxo (o sistema é o que não é).

Do mesmo modo, podemos dizer o que a sociedade é ou, alternativamente, o que não é. Ambas as formas de reflexão, no entanto, não melhoram mas bloqueiam as operações do sistema. (...) Desde que ambas as versões têm a desvantagem de esterilidade, um observador não pode nem adivinhar qual delas será escolhida nem recomendar qual delas escolher; nem ele pode prever que consequências uma ou outra versão de autodescrição terá para o sistema. (LUHMANN et FUCHS, 1988). ${ }^{9}$

O paradoxo e a tautologia conduzem a problemas lógicos e a estratégias de contornálos. Uma das estratégias dos diversos discursos sociais de lidar com o paradoxo é obscurecer seu caráter narrativo (do nível do dizer) e enfatizar seu caráter descritivo (do nível do ver). Ou seja, reduzindo a observação de segunda ordem a uma observação de primeira ordem, pois esta última evita a circularidade uma vez que o sistema realiza uma autodescrição como se observasse um outro sistema. O resultado então é o apagamento da distinção entre o dizer e o ver, e tudo o que é dito é o que foi observado. Em Genette, isso significa o desaparecimento

conceito de descrição, permanecendo sempre uma equivalência entre a descrição e a autodescrição, equivalência essa não inteiramente teorizada em sua obra.

8 "A operação de observar, portanto, inclui a exclusão do inobservável, incluindo, além disso, o inobservável por excelência, a observação em si, o observador-na-operação" "The operation of observing, therefore, includes the exclusion of the unobservable, including, moreover, the unobservable par excellence, observation itself, the observer-in-operation") (Luhmann, 1995, p.44).

9"Correspondingly, we might say society is what it is or, alternatively, society is what is not. Both forms of reflection, however, do not improve but block the operations of the system. (...) Since both versions have the disadvantage of sterelity, an observer can neither guess which one will be chosen nor recommend which one to chose; nor can he predict what consequences one or the other version of self-description will have for the system." 
dos traços do informante (narrador) sob os traços da informação ${ }^{10}$. Com isso, substitui-se a diegesis por uma ilusão de mimesis. É ilusão porque continua sendo um relato e o narrador se tornou apenas "invisível”, mas continua existindo, apesar de obscurecido. Para Luhmann, por seu lado, a sociedade trabalha o paradoxo e a tautologia no recurso à ideologia ${ }^{11}$.

A partir desses conceitos podemos desenvolver a segunda tese deste ensaio: a narrativa literária é sempre narrativa de narrativa, ou uma narrativa de segunda ordem. $\mathrm{Ou}$, em outros termos, a narrativa literária é uma observação da própria narrativa para evidenciar seu caráter distinto de uma mera descrição, que corresponderia a uma observação de primeira ordem. Assim, o discurso literário incluiria o paradoxo ao insistir no jogo entre o nível narrativo e o nível da história. Por isso, na narratologia surge a questão dos níveis narrativos ou diegéticos. Toda narrativa literária nunca é composta de apenas uma única narrativa e uma única história, mas de diversas narrativas apresentadas a partir de várias perspectivas, ou focalizações e, portanto, com várias histórias interiores. Na literatura, a presença da narrativa múltipla, ou "multinarrativa", obriga a presença de níveis, de contrastes e de intervalos, cuja função determinante é justamente fazer aparecer a narrativa a ela própria, sendo um modo de observar a narrativa a partir de si mesma, uma auto-observação.

Esse jogo de múltiplas narrativas lembra o célebre conceito de polifonia do teórico russo Mikhail Bakhtin. Polifonia se refere à variedade de vozes no interior do discurso romanesco. Não é difícil observar que o conceito de polifonia decorre do conceito de "multinarrativa", já que cada voz é um modo do dizer ou contar uma história. Para desdobrar essa discussão, no entanto, é importante trazer o conceito de cronotopo proposto pelo teórico soviético. Cronotopo significa a "interligação fundamental das relações temporais e espaciais artisticamente assimiladas em literatura" (BAKHTIN, 1993, p. 211). Bakhtin, que admite retirar seu conceito

\footnotetext{
10"Genette classifica os relatos em dois grupos: o relato de eventos e o relato das palavras. Os dois tipos de relatos serão menos miméticos, mais ou menos diegéticos. No entanto, o critério no qual esta tipologia é baseada é a quantidade de informações, e ao inverso, a quantidade de informante, em outras palavras, a quantidade de traços do informante. Para fazer este critério operatório, deve-se saber exatamente o que é 'informação' e o que é 'informante'. Genette entende por informação o que é constituída pelo objeto narrado; o máximo de informação é o objeto que é narrado com o máximo de detalhes possível" ("Genette classe les récits em deux groupes: le récit de evénements et le récit de paroles. Les deux tipes de récit seront moins mimétiques, plus ou moins diégétiques. Or, le critère sur lequel cette typologie est basée est la quantité du information, et, em raison inverse, la quantité d'informateur, autrement dit la quantité de traces de l' informateur. Pour que ce critère soit opératoire, il faudrait savoir exactement ce qui est ' information' et ce qui est ' informateur'. Genette entend par information ce qui est constitué par l' objet narré; le maximum d' information est l' objet que est narré avec le plus de détails possible", BAL, 1977, p.111).

11 "O que as abordagens tautológicos e paradoxais de autodescrições societais têm em comum é que elas transformam as descrições da sociedade em ideologias" "What tautological and paradoxical approaches to societal self-descriptions have in common is that they transform descriptions of society into ideologies") (LUHMANN et FUCHS, 1988).
} 
da Teoria da Relatividade einsteiniana, diz também que o cronotopo torna o espaço-tempo "artisticamente visível":

No cronotopo artístico-literário ocorre a fusão dos indícios espaciais e temporais num todo compreensivo e concreto. Aqui o tempo condensa-se, comprime-se, torna-se artisticamente visível; o próprio espaço intensifica-se, penetra no movimento do tempo, do enredo, e da história. Os índices do tempo transparecem no espaço, e o espaço reveste-se de sentido e é medido com o tempo. Esse cruzamento de séries e a fusão de sinais caracterizam o cronotopo artístico (BAKHTIN, 1993, p. 211).

O cronotopo corresponde às extensões temporal e espacial de uma história que a torna "visível" ao leitor através de seu alter-ego, o narratário. O cronotopo é o tecido espaço-temporal do mundo da história narrada. Além da referência à Teoria da Relatividade, Bakhtin também referencia à filosofia kantiana onde tempo e espaço são "formas indispensáveis de qualquer conhecimento" (idem, 212). Mas assim como na teoria einsteiniana todo espaço-tempo é relativo a um sistema de referência, também o cronotopo é um produto do foco narrativo, ou de uma forma de apreender o tempo e o espaço. Assim, não é difícil admitir que o cronotopo é exatamente o objeto narrativo de uma focalização, ou em outros termos, a focalização é a construção literária de um cronotopo; ou ainda, o cronotopo é a extensão espaço-temporal de um foco literário.

Aqui é preciso arriscar uma hipótese a partir das teses apresentadas sobre a narrativa. $\mathrm{O}$ cronotopo surge como uma resolução do paradoxo inerente à narrativa como observação de segunda ordem. Ele substitui, no espaço literário ou ficcional, o recurso à ideologia como obscurecimento do paradoxo da observação de si mesma. Essa hipótese pode ser melhor entendida a partir da distinção proposta por Luhmann entre autorreferência e heterorreferência. Ambas são formas com que o sistema lida com sua distinção do ambiente numa observação. A autorreferência é a referência do sistema a si próprio, enquanto a heterorreferência é como o ambiente é referenciado pelo sistema em seus próprios termos (do sistema). Para Luhmann, a autopoiese de um sistema se dá pela oscilação entre esses dois modos de referência. Essa oscilação introduz o tempo no interior do sistema (pois a resolução é uma questão de tempo) e consequentemente também a extensão espacial.

Em termos narrativos, a autorreferência é a referência ao discurso narrativo, ao relato, ao que é narrado. Trata-se de uma referência comum na literatura moderna, quando o discurso faz aparecer a si sua própria enunciação. A heterorreferência, por sua vez, aponta para o que está fora do discurso, ou seja, para o que está sendo narrado, que é a própria história como "realidade" contextual ou extratextual, "vista" a partir de certo foco.

É preciso, no entanto, atentar que, como insiste Genette, na narrativa literária, nada é realmente "visto", tudo é sempre dito. O que é "visto" é um modo de apresentar o que é dito. 
Por isso, as distinções entre narrativa/história e autorreferência/heterorreferência são eficazes em marcar o que se diferencia no interior do próprio relato. A ênfase na narrativa é a sinalização de um discurso perspectivado por narradores e "focalizadores" que restringem um "campo de informação". O conceito de Genette da mimese como discurso de informação plena é absolutamente pertinente, pois não há a rigor informação completa num relato. A narrativa é um discurso de quem observa e assume uma perspectiva situada.

Por isso, é igualmente importante relacionar a formação do cronotopo como o foco dessa perspectiva situada. Pois o cronotopo é o tecido mesmo da história contada através do tempo e do espaço. Podemos mesmo supor que os personagens são concretizações desse tecido de tempo e espaço exatamente como a matéria na teoria da relatividade einsteiniana é uma dobra de tempo e de espaço. Personagens são curvaturas do cronotopo, pois não apenas o cronotopo permite que os personagens e suas ações se desenvolvam, mas os próprios personagens em suas relações ficcionais dão a ver a formação dos cronotopos. Isto é, os fios narrativos traçam os cronotopos enquanto história desdobrada pela narrativa.

\section{CONSIDERAÇÕES FINAIS}

Para finalizar, podemos dizer que o romance ficcional moderno, em seu aspecto literário, não é simplesmente uma nova forma de narrativa, mas um dispositivo comunicativo que apresenta uma diversidade de narrativas, ou de níveis diegéticos, cujo jogo de contrastes e conflitos revela as diferentes modos de se dizer e de se ver, fazendo emergir o caráter de observação de segunda ordem da narrativa literária, como narrativa da narrativa, ou sua autoobservação. Nestas, as histórias se apresentam como desdobramentos de cronotopos, que são tecidos ficcionais de tempo e de espaço, que se contrastam ou se confrontam a partir de diferentes perspectivas. A autopoiese da literatura seria essa autorreprodução permanente de certo tipo de comunicação social, a narrativa literária, que mantém sempre aberto seu horizonte de efetividade pela constante inclusão do paradoxo entre o que se diz (o que se narra) e o que se vê (o que se observa) e pelo jogo sempre múltiplo dos cronotopos ficcionais. 


\section{REFERENCIAS}

BAKHTIN, Mikhail. Questões de Literatura e Estética. 3a edição. São Paulo: Hucitec, 1993.

BAL, Mieke. Narratology. Introduction to the theory of narrative. Toronto: University of Toronto Press, 1985.

BAL, Mieke. Narration et focalization. Pour une theórie des instances du récit. Poétique, Vol. 29, 1977, p. 107-127. Disponível em: http://dare.uva.nl/search?identifier=0328a9af-99554182-b073-ef148272ac32

CLARKE, Bruce. Neocybernetics and narrative. Minneapolis: University of Minnesota Press, 2014.

FLUSSER, Vilém. Esperando por Kafka. In: FLUSSER, Vilém. Da religiosidade: a literatura e o senso de realidade. São Paulo: Escrituras, 2002.

GENETTE, Gerard. Nouveau discours du récit. Paris: Seuil, 1983.

KORFMANN, Michael. A literatura moderna como observação de segunda ordem. Uma introdução ao pensamento sistêmico de Niklas Luhmann. São Paulo, Revista pandaemonium Germanicum, n.6, 2002. Disponível em: http://www.revistas.usp.br/pg/article/view/64398.

LUHMNANN, Niklas. The concept of autopoiesis. In: SEIDL, David et BECKER, K.h (org.) Niklas Luhmann and Organization Studies. Copenhagen, Liber \& Copenhagen Business School Press, 2006, Disponível em: http://www.bogerogpapir.dk/productsamples/9788763003049.pdf.

. The autopoiesis of social systems. In: SEIDL, David et BECKER, K.h (org.) Niklas Luhmann and Organization Studies. Copenhagen, Liber \& Copenhagen Business School Press, 2006.2 Disponível em: http://www.bogerogpapir.dk/productsamples/9788763003049.pdf.

The paradox of observing systems. Cultural Critique, No. 31, The Politics of

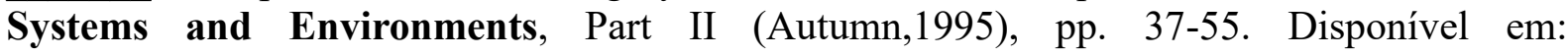
http://www.jstor.org/stable/1354444? origin=JSTOR-pdf.

A obra de arte e a auto-reprodução da arte. In: OLINTO, Heidrun K. História da Literatura e as novas teorias alemãs. São Paulo: Editora Ática, 1996.

LUHMANN, Niklas et FUCHS, Stephan. Tautology and paradox in self-descriptions of modern society. Sociological theory, Volume 6, Issue 1 (spring, 1988) 21-37. Disponível em: http://www.d.umn.edu/cla/faculty/jhamlin/4111/Readings/LuhmannTautology.pdf.

LUKÁCS, Georg. Narrar ou descrever. In: LUKÁCS, Georg. Ensaios sobre literatura. Rio de Janeiro: Editora Civilização Brasileira, 1965.

SEIDL, David. The Basic Concepts of Luhmann's Theory of Social Systems. In: SEIDL, David et BECKER, K.h (org.) Niklas Luhmann and Organization Studies. Copenhagen, Liber \& 
Copenhagen Business School Press, 2006. Disponível em: http://www.bogerogpapir.dk/productsamples/9788763003049.pdf.

SCHOLES, Robert. Structural fabulation: an essay on fiction of the future. South Bend, University of Notre Dame Press, 1975.

STAMFORD DA SILVA, Artur. 10 lições sobre Luhmann. Petrópolis, Vozes, 2016. 